\title{
Working Together to Promote Perineal Integrity in Normal Physiologic Birth: A Joint Collaboration between Women and Midwives
}

\author{
Somayeh Makvandi ${ }^{1}$ and Khadigeh Mirzaiinajmabadi ${ }^{2 *}$ \\ ${ }^{1}$ Department of Midwifery, Mashhad University of Medical Sciences, Iran \\ ${ }^{2}$ Associate Professor, Department of Midwifery, Mashhad University of Medical Sciences, Iran \\ *Corresponding author: Khadigeh Mirzaiinajmabadi, Associate Professor, Department of Midwifery, School of Nursing and Midwifery, Mashhad \\ University of Medical Sciences, Mashhad, Iran
}

Submission: 傮 February 26, 2018; Published: 眥 April 26, 2018

\section{Opinion}

Perineal trauma during childbirth is mainly connected with pain and complications. Episiotomy is a surgical incision of the perineum and the posterior vaginal wall. Before setting up motherfriendly care in Iran, mediolateral episiotomy was a traditional and routine component of vaginal childbirth. The aim was to keep away from damage to the anal sphincter and to limit the risk of traumatic birth for the fetus. In Iran, mother-friendly hospitals started their activity in 2008. A mother-friendly hospital must to promote and support normal physiologic birth that is the vaginal delivery with minimal interventions including routine episiotomies [1]. Evidences comparing routine and restrictive use of episiotomy during spontaneous vaginal birth propose that there are significant advantages in adopting a restrictive approach, particularly a reduction in posterior perineal lacerations [2-4].

According to Iran's Health Ministry's policies, the overall ideal episiotomy rate should be less than $30 \%$ and each motherfriendly hospital is required to reduce the episiotomy rate by $10 \%$. Maintaining women's perineal integrity is a highly respected point in physiologic childbirth techniques. In the physiologic birth program, expectant women are advised to perform a perineal massage six to eight weeks prior to birth. Antenatal perineal massage increases both the overall health and elasticity of the perineum. Also, pregnant women who perform Kegel or pelvic floor exercises often find they have more intact perineum during delivery. A full Kegel involves pulling up and then pulling in or engaging the inner muscles and then the surface muscles of the pelvic floor.
In the second stage of labor, a slow and controlled birth of the baby is believed to be of significance to prevent perineal injury. The women should let their bodies tell them when to push. The whole reason the pushing stage is a slow process is to permit their tissues time to stretch. Application of the "Hands-off" approach for delivery of fetal head and support the birth of the shoulders by midwives has a positive effect on protecting the integrity of perineum and reducing the number and severity of perineal lacerations. As mentioned above, in the physiologic birth program maintaining an intact perineum is a joint collaboration between women and midwives.

\section{References}

1. (2011) A national guide for normal delivery and the provision of pharmacological and nonpharmaceutical methods for reducing labor pain. Iran's Ministry of Health and Medical Education. Maternity Health Office, Family and Population Health Office, Iran.

2. Yamasato K, Kimata C, Huegel B, Durbin M, Ashton M, et al. (2016) Restricted episiotomy use and maternal and neonatal injuries: a retrospective cohort study. Arch Gynecol Obstet 294(6): 1189-1194.

3. Venus D, Rao PS, Prajwal S (2017) Comparison of use of restrictive episiotomy versus routine episiotomy in primigravidae undergoing vaginal birth at a tertiary care hospital. International Journal of Reproduction, Contraception, Obstetrics and Gynecology 6(5): 17701776.

4. Asokan KM, Santhosh S (2016) Routine episiotomy causes more morbidity in parous women, a case controlled study conducted in Kannur Medical College. Age 5(18): 902-904. 

(c) (1) Creative Commons Attribution 4.0

For possible submissions Click Here

Submit Article

\section{PRM Iminem \\ Perceptions in Reproductive Medicine}

\section{Benefits of Publishing with us}

- High-level peer review and editorial services

- Freely accessible online immediately upon publication

- Authors retain the copyright to their work

- Licensing it under a Creative Commons license

- Visibility through different online platforms 